\title{
Association Between Hypoglycemia and Fall-Related Events in Type 2 Diabetes Mellitus: Analysis of a U.S. Commercial Database
}

\author{
Sumesh Kachroo, PhD; Hugh Kawabata, MS; Susan Colilla, PhD, MPH; Lizheng Shi, PhD; \\ Yingnan Zhao, PhD; Jayanti Mukherjee, PhD; Uchenna Iloeje, MD, MPH; and Vivian Fonseca, MD
}

\begin{abstract}
BACKGROUND: Hypoglycemia is a major barrier to achieving optimal glycemic control and managing diabetes successfully in patients with diabetes. Falls are the most significant consequences caused by hypoglycemia episodes. Both hypoglycemia and falls lead to substantial economic burden on the health care system in the United States.
\end{abstract}

OBJECTIVE: To examine the association of hypoglycemia with fall-related outcomes in elderly patients with type 2 diabetes mellitus (T2DM).

METHODS: Records were obtained for T2DM patients $(\mathrm{N}=1,147,937)$ from January 1,2008 , to December 31,2011 . The nonhypoglycemia patients were randomly matched $1: 1$ by age and gender to the hypoglycemia patients. Fall-related events (composite of fall-related outcomes) were defined using ICD-9-CM codes. Conditional logistic regression models were used to compare the fall-related events within 30 days, 90 days, 180 days, and 365 days between the 2 cohorts.

RESULTS: A total of 21,613 hypoglycemia patients were matched with 21,613 nonhypoglycemic patients. Patients with hypoglycemia had higher fall-related events within 30 days, 90 days, 180 days, and 365 days $(P<0.001$ for all frequency differences). Conditional logistic regression analyses showed an elevated risk for fall-related events over 365 days (aOR=1.95, 95\% $\mathrm{Cl}=1.70-2.24)$. Subgroup analysis showed elevated risk for patients aged $<75$ years and $\geq 75$ years. Elevated risks were also seen for individual fall-related outcomes of fractures, head injuries, long-term care placement, and hospital admissions.

CONCLUSIONS: The risk of fall-related events over 365 days increased 2-fold among elderly patients with diabetes who experienced hypoglycemia.

J Manag Care Spec Pharm. 2015;21(3):243-53

Copyright $\odot 2015$, Academy of Managed Care Pharmacy. All rights reserved.

\section{What is already known about this subject}

Hypoglycemia is a major barrier to achieving optimal glycemic control and managing diabetes successfully in patients with diabetes. Falls are the most significant consequences caused by hypoglycemia episodes.

Hypoglycemia and falls lead to substantial economic burden on the health care system in the United States.

Currently, there exists limited evidence reporting the association between hypoglycemia and fall-related events among elderly diabetes patients in the United States.

\section{What this study adds}

This study reported the association between hypoglycemia and fall-related events among elderly diabetes patients and highlighted an increased risk of fall-related events among elderly patients with diabetes who experienced hypoglycemia.

The analyses reported the association overall for all fall-related events as well as for the specific fall-related outcomes, which included fractures, head injury, long-term care placement, and hospitalizations.

This study provides a real-world picture of elderly diabetic patients who experience hypoglycemia.

T ype 2 diabetes mellitus (T2DM) is a progressive disorder with more than 347 million people worldwide suffering from this disease. ${ }^{1}$ It results in at least a 2-fold increase in the risk of death and, hence, has become a major global concern. ${ }^{1}$ As per 2012 U.S. estimates, about 22.3 million people ( $\sim 7 \%$ of the U.S. population) have been diagnosed with diabetes, leading to an estimated economic burden of $\$ 245$ billion ( $\$ 176$ billion in direct medical costs and $\$ 69$ billion in indirect costs). ${ }^{2}$ Diabetes leads to an increase in the risk of macrovascular and microvascular complications, thereby predisposing these patients to hospitalization. ${ }^{3-5}$ Oral antidiabetes medications are used to control the glycemic levels in patients with diabetes; however, some of these medications have been linked to an increased risk of hypoglycemia (abnormally low blood sugar levels $<70$ milligrams per deciliter). ${ }^{1,4,5}$ Consequently, hypoglycemia has remained 1 of the critical limiting factors that has troubled health care providers in achieving optimal glycemic control and managing diabetes successfully in these patients.

Hypoglycemia leads to a substantial economic burden on the health care system, as highlighted by studies from across the globe. The direct medical costs spent on treating hypoglycemia range from approximately $\$ 188$ to $\$ 2,100$ per episode, depending on disease severity and the extent of medical care needed, while the indirect costs are approximately $\$ 3,169$ per patient per year due to lost productivity. ${ }^{6}$ A population-based Scottish study reported that the annual direct cost of treating severe hypoglycemia in the United Kingdom could exceed $£ 13$ million ( $\$ 21$ million). ${ }^{7}$ A Spanish study has reported the cost of hypoglycemia as approximately $€ 3,500(\sim 4,700)$ per 
episode of severe hypoglycemia. ${ }^{8}$ A Korean study reported costs ranging from $\$ 135.50$ to $\$ 1,391.00$ per episode of severe hypoglycemia. ${ }^{9}$ Swedish studies report the direct costs of hypoglycemia per patient being $\$ 12.90$ for a 1-month period, while the indirect costs are $\$ 14.10$ for a 1-month period, with the total cost (in base case) of hypoglycemia in Sweden being approximately $€ 4,250,000$ ( $\sim 5.74$ million) per year. ${ }^{10,11}$ In addition to an increase in health care utilization and costs, hypoglycemia also leads to decline in the quality of life of the patients. ${ }^{6,12,13}$

In the United States, falls remain a critical issue of concern, since they are a major cause of morbidity and mortality in the elderly population, with current literature suggesting that the economic burden of falls may reach $\$ 54.9$ billion in $2020 .^{14,15}$ The most common nonfatal outcome of falls is fractures, which constitutes approximately $61 \%$ of all fall-related costs, with other outcomes being injuries to internal organs, traumatic brain injuries including subdural hematomas, injuries resulting in surgical interventions, and even death. ${ }^{15,16}$ A study at 3 midwestern hospitals reported that the operational costs for fallers with serious injury (fracture, subdural hematoma, any injury resulting in surgical intervention, or death) were $\$ 13,316$ higher than inpatient controls who do not experience a fall, with an additional 6.3 days of hospital stay needed for the average faller in the general population. ${ }^{16}$ The study also indicated that the fallers were significantly more likely to have diabetes with preexisting organ damage.

A recent study of Medicare-covered patients with T2DM by Johnston et al. (2012) reported 70\% higher adjusted odds of fall-related fractures among patients with hypoglycemic events as compared with patients without hypoglycemic events. ${ }^{15}$ Signorovitch et al. (2013) reported that in patients with T2DM who received antidiabetes drugs without insulin, hypoglycemia was associated with a significantly higher risk of accidents that resulted in hospital visits (hazard ratio $[\mathrm{HR}]=1.39,95 \%$ confidence interval $[\mathrm{CI}]=1.21-1.59)$, accidental falls ( $\mathrm{HR}=1.36$, 95\% CI $=1.13-1.65$ ), and motor vehicle accidents ( $\mathrm{HR}=1.82$, 95\% CI = 1.18-2.80). ${ }^{17}$ Currently, a dearth of literature exists on studies evaluating the association between hypoglycemia and various key fall-related outcomes. The objective of this study was to examine the association between hypoglycemia and fall-related events (a composite of all fall-related outcomes) among elderly diabetes patients. This examination included the association overall for all fall-related events, as well as for the specific fall-related outcomes, which included fractures, head injury, long-term care placement, and hospitalizations.

\section{Methods}

A retrospective cohort study was conducted in patients with T2DM. Records were obtained from Truven Health MarketScan Medicare Supplemental Database for patients with at least 2 records of T2DM diagnosis from January 1, 2008, to December
31, 2011. Patients were required to be aged $\geq 65$ years at index date (first T2DM date in the study period). The first date of a recorded hypoglycemia diagnosis (International Classification of Diseases, Ninth Revision, Clinical Modification [ICD-9-CM] codes 250.8, 251.0, 251.1, and 251.2) was defined as the cohort entry date for patients in the hypoglycemia group (HG) ${ }^{18}$ A 6-month baseline and 1-year follow-up period from cohort entry date was required. Patients in the nonhypoglycemia group (NHG) were 1:1 randomly matched by age and gender. For the NHG patients, their cohort entry dates were kept the same as their respective matched patients from the HG.

Fall-related events were defined as ICD-9-CM codes 800.x-995.x, with a fall being the external cause defined as ICD-9-CM E-codes E880-E888, which were recorded within \pm 2 days of each other in any order. ${ }^{15,19}$ In administrative claims data, the ICD-9-CM diagnosis coding for fracture sites does not possess a level of specificity that allows identification of whether a fall specifically caused a fracture. To determine whether a fall caused a fracture, ICD-9-CM Index to External Cause of Injury codes (E codes) is still employed, even though E codes may be flawed. The approach is the best we can do at this time, and the limitation of using E codes to define fall-related events is recognized by the Centers for Disease Control and Prevention. ${ }^{20}$ ICD-9-CM codes were also used to capture the 2 individual outcomes: hospitalizations (inpatients) and long-term care placements. In addition to ICD-9-CM codes, provider type codes, place of service codes, discharge status codes, and procedure codes were used to identify long-term care placement patients. ICD-9-CM codes for fractures included 800.x-839.x, with a fall being the external cause defined as ICD-9-CM E-codes E880-E888. Head injuries were defined as ICD-9-CM codes 800.x-804.x, 850.x-854.x, 905.0, 907.0, and 873, with a fall being the external cause defined as ICD-9-CM E-codes between E880-E888. The ICD-9-CM codes for fractures and head injuries were verified and finalized from the ICD-9-CM coding book. If 2 claims were observed within 30 days of each other, they were assessed as the result of the same fall event.

\section{Statistical Analysis}

Two study cohorts were formed. The first cohort (HG) included those patients who had at least 1 claim for hypoglycemia. The data of the first such claim during the study period was considered the patient's cohort entry date. The 6-month period immediately prior to this cohort entry date was considered the baseline period. The 12-month period following this cohort entry date was the follow-up period. The NHG cohort was randomly formed, by assigning a cohort entry date to those patients who did not have a hypoglycemia claim such that the mean days between the index date of the patient and this cohort entry date was the same as in the HG cohort. The NHG cohort was 1:1 randomly matched by age and gender to patients in the HG cohort. 
TABLE 1 Demographic Characteristics, Comorbidities, and Medication Use in the Baseline Period

\begin{tabular}{|c|c|c|c|c|c|c|}
\hline \multirow[b]{2}{*}{ Demographic Characteristics } & \multicolumn{2}{|c|}{$\begin{array}{c}\text { Hypoglycemia Patients } \\
\mathrm{N}=21,613\end{array}$} & \multicolumn{2}{|c|}{$\begin{array}{l}\text { Nonhypoglycemia Patients } \\
\qquad \mathrm{N}=21,613\end{array}$} & \multirow{2}{*}{$\begin{array}{l}\text { McNemar's } \\
\text { Test Statistic }\end{array}$} & \multirow[b]{2}{*}{$P$ Value } \\
\hline & $\mathrm{N}$ & $\%$ & $\mathrm{~N}$ & $\%$ & & \\
\hline \multicolumn{7}{|l|}{ Age group } \\
\hline $65-69$ & 8,678 & 40 & 8,678 & 40.15 & NS & NS \\
\hline $70-74$ & 4,849 & 22 & 4,849 & 22.44 & NS & NS \\
\hline $75-79$ & 4,511 & 21 & 4,511 & 20.87 & NS & NS \\
\hline $80-84$ & 2,595 & 12 & 2,595 & 12.01 & NS & NS \\
\hline $85-89$ & 840 & 4 & 840 & 3.89 & NS & NS \\
\hline $90-94$ & 128 & 1 & 128 & 0.59 & NS & NS \\
\hline $95-100$ & 11 & 0 & 11 & 0.05 & NS & NS \\
\hline$\geq 100$ & 1 & 0 & 1 & 0.00 & NS & NS \\
\hline \multicolumn{7}{|l|}{ Gender } \\
\hline Male & 10,494 & 48.55 & 10,494 & 48.55 & NS & NS \\
\hline Female & 11,119 & 51.45 & 11,119 & 51.45 & NS & NS \\
\hline \multicolumn{7}{|l|}{ U.S. census region } \\
\hline North East & 4,068 & 18.82 & 3,865 & 17.88 & 6.42 & 0.0116 \\
\hline North Central & 7,395 & 34.22 & 6,639 & 30.72 & 60.59 & $<0.0001$ \\
\hline South & 6,069 & 28.08 & 6,321 & 29.25 & 7.32 & 0.0070 \\
\hline West & 3,562 & 16.48 & 3,858 & 17.85 & 14.36 & 0.0002 \\
\hline Unknown & 519 & 2.40 & 930 & 4.30 & - & - \\
\hline \multicolumn{7}{|l|}{ Plan type } \\
\hline Comprehensive & 8,749 & 40.48 & 7,511 & 34.75 & 154.00 & $<0.0001$ \\
\hline EPO & 102 & 0.47 & 36 & 0.17 & 31.56 & $<0.0001$ \\
\hline $\mathrm{HMO}$ & 3,250 & 15.04 & 3,045 & 14.09 & 7.94 & 0.0051 \\
\hline POS & 401 & 1.86 & 504 & 2.33 & 11.85 & 0.0006 \\
\hline $\mathrm{PPO}$ & 8,135 & 37.64 & 9,625 & 44.53 & 216.21 & $<0.0001$ \\
\hline POS with capitation & 15 & 0.07 & 33 & 0.15 & 6.75 & 0.0133 \\
\hline CDHP & 81 & 0.37 & 159 & 0.74 & 25.78 & $<0.0001$ \\
\hline HDHP & 11 & 0.05 & 12 & 0.06 & 0.04 & 1.0000 \\
\hline Missing & 869 & 4.02 & 688 & 3.18 & - & - \\
\hline \multicolumn{7}{|l|}{ Falls in the baseline period ${ }^{a}$} \\
\hline Yes & 637 & 2.95 & 238 & 1.10 & 184.90 & $<0.0001$ \\
\hline No & 20,976 & 97.05 & 21,375 & 98.90 & 184.90 & $<0.0001$ \\
\hline \multicolumn{7}{|l|}{ Medication } \\
\hline Metformin & 4,883 & 22.6 & 5,302 & 24.5 & 22.70 & $<0.0001$ \\
\hline Sulfonylurea & 8,651 & 40.0 & 4,594 & 21.3 & $1,728.37$ & $<0.0001$ \\
\hline Thiazolidinediones & 2,794 & 12.9 & 2,081 & 9.6 & 119.64 & $<0.0001$ \\
\hline Insulin ${ }^{\mathrm{b}}$ & 4,531 & 21.0 & 1,474 & 6.8 & $1,739.94$ & $<0.0001$ \\
\hline \multicolumn{7}{|l|}{ Comorbidities $^{c}$} \\
\hline Cardiovascular events & 945 & 4.4 & 289 & 1.3 & 364.07 & $<0.0001$ \\
\hline Stroke & 1,798 & 8.3 & 681 & 3.2 & 526.23 & $<0.0001$ \\
\hline Obesity & 851 & 3.9 & 472 & 2.2 & 113.19 & $<0.0001$ \\
\hline Dyslipidemia & 8,519 & 39.4 & 7,151 & 33.1 & 188.04 & $<0.0001$ \\
\hline Atherosclerosis & 1,990 & 9.2 & 1,030 & 4.8 & 327.04 & $<0.0001$ \\
\hline Hypertension & 14,431 & 66.8 & 11,214 & 51.9 & 984.41 & $<0.0001$ \\
\hline Nephropathy & 273 & 1.3 & 87 & 0.4 & 96.64 & $<0.0001$ \\
\hline Diabetic foot problem & 7 & 0.0 & 3 & 0.0 & 1.60 & 0.3438 \\
\hline Diabetes with neurological manifestations & 11 & 0.1 & 3 & 0.0 & 4.57 & 0.0574 \\
\hline Dental disease & 30 & 0.1 & 24 & 0.1 & 0.67 & 0.4966 \\
\hline Osteoporosis & 1,035 & 4.8 & 789 & 3.7 & 35.35 & $<0.0001$ \\
\hline Chronic kidney disease & 4,224 & 19.5 & 1,626 & 7.5 & $1,313.15$ & $<0.0001$ \\
\hline Hyperparathyroidism & 592 & 2.7 & 201 & 0.9 & 195.25 & $<0.0001$ \\
\hline Impaired vitamin D deficiency & 591 & 2.7 & 345 & 1.6 & 67.24 & $<0.0001$ \\
\hline Depression & 1,547 & 7.2 & 742 & 3.4 & 300.43 & $<0.0001$ \\
\hline Arthritis & 4,570 & 21.1 & 3,300 & 15.3 & 249.29 & $<0.0001$ \\
\hline
\end{tabular}


TABLE 1 Demographic Characteristics, Comorbidities, and Medication Use in the Baseline Period (continued)

\begin{tabular}{|c|c|c|c|c|c|c|}
\hline \multirow[b]{2}{*}{ Demographic Characteristics } & \multicolumn{2}{|c|}{$\begin{array}{l}\text { Hypoglycemia Patients } \\
\qquad \mathrm{N}=21,613\end{array}$} & \multicolumn{2}{|c|}{$\begin{array}{l}\text { Nonhypoglycemia Patients } \\
\qquad \mathrm{N}=21,613\end{array}$} & \multirow{2}{*}{$\begin{array}{l}\text { McNemar's } \\
\text { Test Statistic }\end{array}$} & \multirow[b]{2}{*}{$P$ Value } \\
\hline & $\mathbf{N}$ & $\%$ & $\mathbf{N}$ & $\%$ & & \\
\hline Leg and foot amputation & 43 & 0.2 & 8 & 0.0 & 24.02 & $<0.0001$ \\
\hline Impaired vision & 1,430 & 6.6 & 637 & 2.9 & 317.44 & $<0.0001$ \\
\hline Lack of urine control & 649 & 3.0 & 414 & 1.9 & 53.15 & $<0.0001$ \\
\hline Dizziness & 1,964 & 9.1 & 924 & 4.3 & 397.35 & $<0.0001$ \\
\hline Low blood pressure & 1,269 & 5.9 & 417 & 1.9 & 444.79 & $<0.0001$ \\
\hline Fainting & 1,847 & 8.5 & 621 & 2.9 & 638.52 & $<0.0001$ \\
\hline Any mental health-related disorderd & 5,084 & 23.5 & 2,319 & 10.7 & $1,234.10$ & $<0.0001$ \\
\hline \multicolumn{7}{|c|}{ 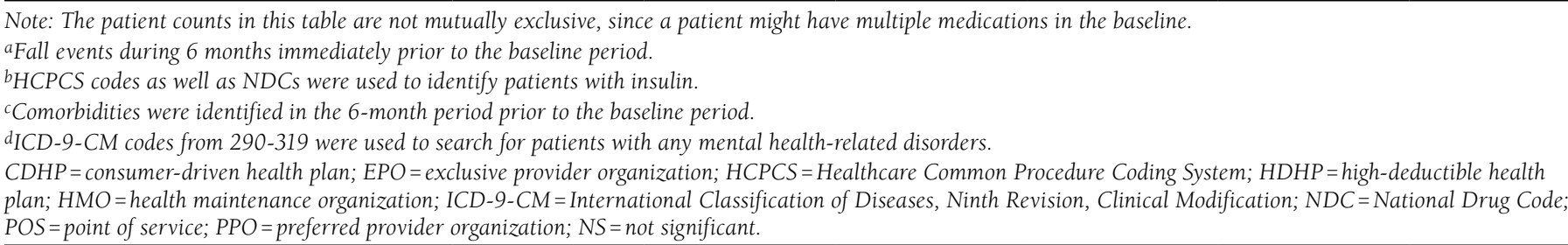 } \\
\hline
\end{tabular}

Comparison of the baseline categorical variables was reported as percentages and baseline continuous variables as means \pm standard deviation (SD) for both of these cohorts. McNemar's test statistic was used to test the comparison of baseline characteristics between cohorts. Due to the matched study design, conditional logistic regression models were used to compare fall-related events within 30 days, 90 days, 180 days, and 365 days between the 2 cohorts in the follow-up period. Adjusted odds ratios (aOR) and corresponding 95\% CIs, controlling for baseline characteristics and comorbidities, were estimated from logistic regression models. Understanding that matching on age and gender do not sufficiently control for all potential confounders, the regression models were adjusted for Charlson Comorbidity Index (CCI) scores. Subgroup analyses for age (aged $<75$ years and $\geq 75$ years) were also conducted. The association between hypoglycemia and fall-related events among elderly diabetes patients with recurrent hypoglycemia was also evaluated. All analyses were done using SAS 9.2 (SAS Institute, Inc., Carey, NC). Statistical significance was defined as a $P<0.05$ (two-tailed).

\section{Results}

A total of 1,147,937 patients with at least 2 records of T2DM diagnosis from January 1, 2008, to December 31, 2011, were available for the analyses. A total of 21,613 hypoglycemia patients were matched with 21,613 patients with no hypoglycemia. Table 1 provides the baseline demographics and comorbidities data. In the hypoglycemia cohort, most of the patients were aged $65-69$ years (40\%), female (51.4\%), from the North Central region (34.2\%), and had comprehensive insurance $(40.5 \%)$. The most common comorbidities in the HG included hypertension (66.8\%) followed by dyslipidemia
(39.4\%), any mental health-related disorder (23.5\%), arthriitis (21.1\%), and chronic kidney disease (19.5\%). A significantly higher proportion of patients with hypoglycemia had comorbidities compared with patients with no hypoglycemia, and this was true for all comorbidities (Table $1 ; P \leq 0.001$ for all comorbidities, except diabetic foot problem $[P=0.344]$, diabetes with neurological manifestations $[P=0.057]$, and dental disease $[P=0.497])$. The mean CCI score was $1.99( \pm 2.31)$ for hypoglycemia patients, compared with $0.95( \pm 1.55)$ for nonhypoglycemia patients $(P<0.001)$. Forty percent of the patients in the HG had been prescribed sulfonylureas.

Patients with hypoglycemia consistently had higher fallrelated events: 235 events (1.09\%) among the HG patients and 37 events $(0.17 \%)$ among the NHG patients within 30 days; 373 events (1.73\%) and 118 events (0.55\%) within 90 days; 520 events (2.41\%) and 204 events (0.94\%) within 180 days; and 720 events (3.33\%) and 351 events (1.62\%) within 1 year. All frequency differences between HG patients and NHG patients were statistically significant $(P<0.001$; Table 2$)$. Conditional logistic regression analyses showed an elevated risk of fallrelated events over 365 days ( $\mathrm{aOR}=1.95,95 \% \mathrm{CI}=1.70-2.24)$. The subgroup analyses by age for the 365-day analysis showed elevated risk for both age groups: aged $<75$ years $(\mathrm{aOR}=2.20$, $95 \% \mathrm{CI}=1.77-2.73)$ and aged $\geq 75$ years $(\mathrm{aOR}=1.77,95 \%$ $\mathrm{CI}=1.48-2.12$ ). Elevated risks were seen for other time points as well, which included within 30 days, within 90 days, and within 180 days. These analyses highlight the greatest risk of fall-related events within the first 30 days $(\mathrm{aOR}=5.86,95 \%$ $\mathrm{CI}=4.08-8.43$ ), with the risk gradually decreasing over time. Table 2 shows the results for all fall-related events by groups. The analyses shown in Table 2 were replicated using relative risk (RR) as a different summary measure (see Appendix A). 
TABLE 2 Fall-Related Events by Group (Including 30-Day to 1-Year Definition Sensitivity Analysis)

\begin{tabular}{|c|c|c|c|c|c|c|c|c|}
\hline \multirow[b]{3}{*}{ Fall Eventsa,b } & \multirow[b]{3}{*}{ Total } & \multirow{2}{*}{\multicolumn{2}{|c|}{$\begin{array}{l}\text { Hypoglycemia Group } \\
\mathrm{N}=21,613\end{array}$}} & \multirow{2}{*}{\multicolumn{2}{|c|}{$\begin{array}{c}\text { Nonhypoglycemia Group } \\
\qquad \mathrm{N}=21,613\end{array}$}} & \multicolumn{3}{|c|}{ Conditional Logistic Regression ${ }^{\mathrm{d}}$} \\
\hline & & & & & & \multirow{2}{*}{$\begin{array}{l}\text { Adjusted Odds } \\
\text { Ratioc }\end{array}$} & \multicolumn{2}{|c|}{ 95\% Confidence Limits } \\
\hline & & $\mathbf{N}$ & $\%$ & $\mathrm{~N}$ & $\%$ & & Lower & Upper \\
\hline Within 30 days & 272 & 235 & 1.09 & 37 & 0.17 & 5.86 & 4.08 & 8.43 \\
\hline Aged $<75$ years & 117 & 107 & 0.50 & 10 & 0.05 & 10.34 & 4.94 & 21.62 \\
\hline Aged $\geq 75$ years & 155 & 128 & 0.59 & 27 & 0.12 & 4.52 & 2.94 & 6.94 \\
\hline Within 90 days & 491 & 373 & 1.73 & 118 & 0.55 & 2.91 & 2.34 & 3.62 \\
\hline Aged $<75$ years & 211 & 165 & 0.76 & 46 & 0.21 & 3.07 & 2.17 & 4.36 \\
\hline Aged $\geq 75$ years & 280 & 208 & 0.96 & 72 & 0.33 & 2.77 & 2.09 & 3.67 \\
\hline Within 180 days & 724 & 520 & 2.41 & 204 & 0.94 & 2.40 & 2.02 & 2.85 \\
\hline Aged $<75$ years & 319 & 238 & 1.10 & 81 & 0.37 & 2.56 & 1.95 & 3.35 \\
\hline Aged $\geq 75$ years & 405 & 282 & 1.30 & 123 & 0.57 & 2.27 & 1.81 & 2.85 \\
\hline Within 365 days & 1,071 & 720 & 3.33 & 351 & 1.62 & 1.95 & 1.70 & 2.24 \\
\hline Aged $<75$ years & 470 & 335 & 1.55 & 135 & 0.62 & 2.20 & 1.77 & 2.73 \\
\hline Aged $\geq 75$ years & 601 & 385 & 1.78 & 216 & 1.00 & 1.77 & 1.48 & 2.12 \\
\hline \multicolumn{9}{|c|}{$\begin{array}{l}\text { ancludes patients with baseline fall events. } \\
\text { bComposite fall events identified by ICD-9-CM codes 800.x-995.x and E codes E880-E888 occurring within } 2 \text { days. } \\
\text { cBy baseline characteristics, Charlson Comorbidity Index, and comorbidities. } \\
\text { dMatched on age and gender. }\end{array}$} \\
\hline
\end{tabular}

The interpretation of the results remained the same, regardless of the summary measure used. The analyses shown in Appendix A were also done excluding any patient in a matched pair who used insulin at baseline (see Appendix B). Compared with Appendix A, the risk of falls in the HG were even higher when insulin users were excluded (particularly notable at 30-day and 90-day estimates).

For the analyses on individual fall-related outcomes (Table 3), conditional logistic regression analyses showed an elevated risk of fracture events for the 365-day analysis ( $\mathrm{aOR}=2.16,95 \%$ $\mathrm{CI}=1.74-2.67$ ). All analyses presented in this paragraph are for the 365-day time period. The subgroup analyses by age showed elevated risk for both age groups: aged $<75$ years $(\mathrm{aOR}=2.30$, $95 \% \mathrm{CI}=1.63-3.24)$ and aged $\geq 75$ years $(\mathrm{aOR}=2.07,95 \%$ $\mathrm{CI}=1.58-2.72$ ). Elevated risks were also seen for head injuryrelated events ( $\mathrm{aOR}=1.63,95 \% \mathrm{CI}=1.22-2.19)$. The subgroup analyses by age showed elevated risk for both age groups: aged $<75$ years $(\mathrm{aOR}=1.77,95 \% \mathrm{CI}=1.08-2.89)$ and aged $\geq 75$ years $(\mathrm{aOR}=1.56,95 \% \mathrm{CI}=1.08-2.24)$. For the analyses of all fall-related hospital admissions, conditional logistic regression analyses showed an elevated risk $(\mathrm{aOR}=2.20,95 \% \mathrm{CI}=1.57$ 3.08). The subgroup analyses by age showed elevated risk for both age groups: $<75$ years $(\mathrm{aOR}=2.24,95 \% \mathrm{CI}=1.22-4.13)$ and $\geq 75$ years $(\mathrm{aOR}=2.20,95 \% \mathrm{CI}=1.45-3.34)$. Elevated risks were also seen for patients with long-term care placement days $(\mathrm{aOR}=2.59,95 \% \mathrm{CI}=1.93-3.46)$. The subgroup analyses by age showed elevated risk for both age groups: $<75$ years $(\mathrm{aOR}=3.75,95 \% \mathrm{CI}=2.10-6.69)$ and $\geq 75$ years group $(\mathrm{aOR}=2.20,95 \% \mathrm{CI}=1.57-3.10)$. The analyses shown in Table
2 were also replicated using RR as a different summary measure (see Appendix C). Again, the interpretation of the results remained the same, regardless of the summary measure used.

For all the individual fall-related outcomes, elevated risks were also seen for other time points as well, which included within 30 days, within 90 days, and within 180 days (data not shown). For individual fall-related outcomes as well, the analyses highlighted the greatest risk within the first 30 days, with the risk gradually decreasing over time (data not shown).

Additional analyses on all composite fall-related events in patients with recurring hypoglycemia (Table 4) also showed an elevated risk over 365 days $(\mathrm{aOR}=2.43,95 \% \mathrm{CI}=1.95-3.02)$. The subgroup analyses by age for the 365-day analysis showed elevated risk for both age groups: $<75$ years $(\mathrm{aOR}=2.32,95 \%$ $\mathrm{CI}=1.64-3.27)$ and $\geq 75$ years $(\mathrm{aOR}=2.47,95 \% \mathrm{CI}=1.85-3.28)$. Elevated risks were seen for other time points as well, which included within 30 days, within 90 days, and within 180 days. The greatest risk of fall-related events was within the first 30 days $(\mathrm{aOR}=12.41,95 \% \mathrm{CI}=6.24-24.67)$, with the risk gradually decreasing over time.

We also ran the regression analysis for all fall outcomes adjusting for CCI and falls at baseline. The change in the aORs was very minimal (less than a $10 \%$ difference in aORs was found) when we included falls in the baseline period as a covariate in addition to the CCI score in the regression model. For example, aOR $=1.95,95 \% \mathrm{CI}=1.70-2.24$ for all fall-related events within 365 days instead of 2.16 as previously noted. Hence, we have presented the results for the model adjusted for the CCI score only. 


\begin{tabular}{|c|c|c|c|c|c|c|c|c|}
\hline \multirow[b]{3}{*}{ Fall Events ${ }^{a, b}$} & \multirow[b]{3}{*}{ Total } & \multirow{2}{*}{\multicolumn{2}{|c|}{$\begin{array}{l}\text { Hypoglycemia Group } \\
\mathrm{N}=21,613\end{array}$}} & \multirow{2}{*}{\multicolumn{2}{|c|}{$\begin{array}{c}\text { Nonhypoglycemia Group } \\
\mathrm{N}=21,613\end{array}$}} & \multicolumn{3}{|c|}{ Conditional Logistic Regression ${ }^{\mathrm{d}}$} \\
\hline & & & & & & \multirow{2}{*}{$\begin{array}{c}\text { Adjusted } \\
\text { Odds Ratio } \\
\end{array}$} & \multicolumn{2}{|c|}{ 95\% Confidence Limits } \\
\hline & & $\mathrm{N}$ & $\%$ & $\mathrm{~N}$ & $\%$ & & Lower & Upper \\
\hline All fracture-related events & 445 & 308 & 1.43 & 137 & 0.63 & 2.16 & 1.74 & 2.67 \\
\hline Aged $<75$ years & 182 & 129 & 0.60 & 53 & 0.25 & 2.30 & 1.63 & 3.24 \\
\hline Aged $\geq 75$ years & 263 & 179 & 0.83 & 84 & 0.39 & 2.07 & 1.58 & 2.72 \\
\hline All head injury-related events & 222 & 145 & 0.67 & 77 & 0.36 & 1.63 & 1.22 & 2.19 \\
\hline Aged $<75$ years & 85 & 58 & 0.27 & 27 & 0.12 & 1.77 & 1.08 & 2.89 \\
\hline Aged $\geq 75$ years & 137 & 87 & 0.40 & 50 & 0.23 & 1.56 & 1.08 & 2.24 \\
\hline All fall-related hospital admissions & 184 & 128 & 0.59 & 56 & 0.26 & 2.20 & 1.57 & 3.08 \\
\hline Aged $<75$ years & 62 & 46 & 0.21 & 16 & 0.07 & 2.24 & 1.22 & 4.13 \\
\hline Aged $\geq 75$ years & 122 & 82 & 0.38 & 40 & 0.19 & 2.20 & 1.45 & 3.34 \\
\hline $\begin{array}{l}\text { All composite fall-related outcomes for } \\
\text { patients with long-term care placement }\end{array}$ & 260 & 186 & 2.20 & 74 & 0.87 & 2.59 & 1.93 & 3.46 \\
\hline Aged $<75$ years & 88 & 69 & 0.81 & 19 & 0.22 & 3.751 & 2.10 & 6.69 \\
\hline Aged $\geq 75$ years & 172 & 117 & 1.38 & 55 & 0.65 & 2.204 & 1.57 & 3.10 \\
\hline \multicolumn{9}{|c|}{$\begin{array}{l}\text { ancludes patients with baseline falls events. } \\
\text { bComposite fall events identified by ICD-9-CM codes 800.x-995.x and E codes E880-E888 occurring within } 2 \text { days. } \\
\text { cAdjusted odds ratio by baseline characteristics, Charlson Comorbidity Index, and comorbidities. } \\
d_{M} \text { Matched on age and gender. }\end{array}$} \\
\hline
\end{tabular}

\section{Discussion}

This study highlights an increased risk of fall-related events among elderly patients with diabetes who experienced hypoglycemia. In our conditional logistic regression analysis, we observed a 2-fold risk of fall-related events over a 365day period among elderly diabetic patients who experienced hypoglycemia compared with patients without hypoglycemic events. Higher risks were also observed for individual fallrelated outcomes. Signorovitch et al. reported that hypoglycemia was associated with a significantly higher risk of accidental falls resulting in hospital visits. ${ }^{17}$ Johnston et al. have also reported $70 \%$ higher regression-adjusted odds of fall-related fractures among patients with hypoglycemic events as compared with patients without hypoglycemic events after 1 year of follow-up. ${ }^{15}$ However, Johnston et al. only looked at the fracture outcome. Our study looked at fall-related events overall, as well as examined other key fall-related outcomes that included fractures, head injury, long-term care placement, and hospitalizations. Fractures, along with head injuries, may lead to serious complications. Some of the possible fall-inducing symptoms that may be connected with a symptomatic presentation of hypoglycemia have been reported previously in the literature..$^{15}$ A more detailed study is needed to find if a causal link exists between the 2 or if the falls are a result of the neurologic, vascular, and ophthalmic complications associated with diabetes. A more focused approach is also needed to understand our observations in patients with recurring hypoglycemia. The larger ORs that were observed in patients with recurrent hypoglycemia suggest higher risks in those patients.
These patients may require a more careful and monitored approach in the management of diabetes.

For all of the analyses, we observed the greatest risk of fallrelated events (as well as for individual fall-related outcomes) within the first 30 days. Education is the key to minimizing the occurrence of falls. Patients, as well as their caregivers, should be better educated about the high risk of falls, especially within the first 30 days of a hypoglycemic episode, and counseling should be provided so appropriate steps can be taken to minimize the occurrence of falls. In addition to educating patients and caregivers on hypoglycemia-related topics such as definition, symptoms, and risk factors, they should be also trained to recognize and treat these episodes. Our findings also highlight the need for a better patient-monitoring strategy immediately after a hypoglycemic event in diabetic patients.

Previously published literature has evaluated the association between fractures and medications used by diabetic patients. A few studies have evaluated the risk for bone fractures associated with exposure to insulin or other oral hypoglycemic agents. ${ }^{21-23}$ These studies show that a patient's functional level and risk factors for falls should be considered during the drug selection decision-making process, since some of the medications may increase fracture risk and thereby worsen fall-related outcomes. In addition, these studies also show that falls are most likely to occur during hypoglycemic episodes. Some studies, however, contradict these findings. ${ }^{15,21,22}$ Consequently, focused research evaluation of the impact of diabetes medications on risk of falls is needed. The recently published American Diabetes Association and European Association 
TABLE 4 All Composite Fall-Related Outcomes for Patients with Recurring Hypoglycemia (Including 30-Day to 1-Year Definition Sensitivity Analysis), Adjusted for CCI Score

\begin{tabular}{|c|c|c|c|c|c|c|c|c|}
\hline \multirow[b]{3}{*}{ Fall Events ${ }^{a, b}$} & \multirow[b]{3}{*}{ Total } & \multirow{2}{*}{\multicolumn{2}{|c|}{$\begin{array}{c}\text { Recurrent } \\
\text { Hypoglycemia Group } \\
\mathrm{N}=8,472^{\mathrm{c}}\end{array}$}} & \multirow{2}{*}{\multicolumn{2}{|c|}{$\begin{array}{l}\text { Nonhypoglycemia Group } \\
\qquad \mathrm{N}=8,472\end{array}$}} & \multicolumn{3}{|c|}{ Conditional Logistic Regression ${ }^{\mathrm{e}}$} \\
\hline & & & & & & \multirow{2}{*}{$\begin{array}{c}\text { Adjusted } \\
\text { Odds Ratio }^{\mathrm{d}}\end{array}$} & \multicolumn{2}{|c|}{ 95\% Confidence Limits } \\
\hline & & $\mathrm{N}$ & $\%$ & $\mathrm{~N}$ & $\%$ & & Lower & Upper \\
\hline Within 30 days & 137 & 128 & 1.51 & 9 & 0.11 & 12.41 & 6.24 & 24.67 \\
\hline Within 90 days & 241 & 193 & 2.28 & 48 & 0.57 & 3.65 & 2.61 & 5.09 \\
\hline Within 180 days & 345 & 261 & 3.08 & 84 & 0.99 & 3.06 & 2.34 & 4.00 \\
\hline Within 365 days & 491 & 349 & 4.12 & 142 & 1.68 & 2.43 & 1.95 & 3.02 \\
\hline
\end{tabular}

${ }^{a}$ Composite fall events identified by ICD-9-CM codes 800.x-995.x and E codes E880-E888 occurring within 2 days.

bBaseline fall event is allowed; 1:1 match was used.

'Out of 21,613 hypoglycemia patients, only 8,472 patients had recurrent hypoglycemia (defined as at least 2 diagnosis of hypoglycemia on 2 different dates). For these

8,472 patients in the hypoglycemic group, the corresponding 8,472 nonhypoglycemic patients were identified.

${ }^{d}$ Adjusted odds ratio by baseline characteristics, CCI, and comorbidities.

${ }^{e}$ Matched on age and gender.

$C C I=$ Charlson Comorbidity Index; E code = ICD-9-CM Index to External Cause of Injury code; ICD-9-CM = International Classification of Diseases, Ninth Revision, Clinical Modification.

for the Study of Diabetes position statement has also raised concerns about hypoglycemia and sulfonylurea use among the elderly, since they are at highest risk for hypoglycemia. ${ }^{4,5}$ This position statement highlights the fact that sulfonylureas are associated with risk of hypoglycemia and recommend that medications predisposing patients to hypoglycemia should be avoided, since it may worsen myocardial ischemia and may cause dysrhythmias. Existing literature on the association between sulfonylurea use and risk of falls and fall-related fractures is sparse and includes studies that have reported conflicting findings. ${ }^{24}$ Future studies are needed to understand this association given that falls induced by hypoglycemia are the hypothesized mechanism for fractures related to sulfonylurea use. Continuous and intermittent sulfonylurea availability has also been reported as a predictor for hypoglycemia-related hospitalization. ${ }^{25}$ A detailed understanding of sulfonylureas is a critical need, given that an estimated 50\%-66\% T2DM patients use sulfonylureas alone or in combination with other diabetes medications. ${ }^{26}$

Physicians treating elderly diabetes patients need to make treatment decisions that minimize the risk of hypoglycemia thereby avoiding the ensuing complications of falls. Falls lead to an increase in the direct and indirect health care utilization and cost burden, so it is critical to take preventive steps to minimize hypoglycemia in elderly diabetic patients. ${ }^{15}$ Minimizing the hypoglycemic events in these patients may also lead to improvement in their quality of life..$^{15}$ In addition, patients with hypoglycemia may need additional education and other preventive measures to reduce the risk and clinical impact of falls. Research on the merits of diabetes education in T2DM patients has highlighted that the more knowledge and awareness patients have regarding the disease, the more efficient their glycemic control is. ${ }^{27}$ Health care professionals should guide patients in identifying the proper educational resources, as well as educate them on key topics such as influence of nutrition and lifestyle, self-monitoring of blood glucose, knowledge regarding hemoglobin Alc, as well as the need for proper glucose, lipid, and blood pressure control to minimize the development of macrovascular complications.

Hypoglycemia is not often recognized as a risk that could lead to potential health-related consequences in T2DM patients. ${ }^{28}$ In 2011, it was reported that patients with diabetes are aware of the importance of controlling blood sugar, but they may not know the risks associated with extremely low blood sugar. ${ }^{29} \mathrm{~A}$ recent publication has revealed that there could be underreporting of this issue because of patient discomfort in disclosing hypoglycemia with treating physicians due to fear of losing driving licenses or jobs, especially with regard to serious or frequent events. ${ }^{30} \mathrm{~A}$ recent survey also revealed that almost one-third of patients surveyed (32\%) said they do not regularly discuss hypoglycemia with their physicians, in part because of patients' limited understanding of hypoglycemia and lack of time, highlighting a need for improving patient and physician communication. ${ }^{31}$ Hypoglycemia unawareness further complicates the situation, which leads to more underreporting of hypoglycemic incidences. ${ }^{32}$

In addition to underreporting, the longer-term impact of hypoglycemia is also not well characterized. If one looks only at emergency room visits and hospitalizations, the true impact of hypoglycemia will be underestimated. A recent survey conducted in Germany, France, and the United Kingdom has shown the potential scale in a real-world setting of what the authors refer to as "hidden costs" associated with hypoglycemia, including absenteeism from work and disturbance of daily life due to fear of hypoglycemia. ${ }^{33}$ 
Finally, frequently occurring hypoglycemia is associated with increased morbidity and mortality. Mild episodes can cause unpleasant symptoms and disrupt daily activities, while severe hypoglycemia can result in disorientation and unusual behavior and may be life threatening. Severe hypoglycemia was a predictor of cardiovascular mortality in the Action to Control Cardiovascular Risk in Diabetes trial, with a previous occurrence of severe hypoglycemia being an important predictor of a primary cardiovascular event. ${ }^{34}$ Also, in the Veterans Affairs Diabetes Trial, hypoglycemia was an important predictor of cardiovascular death. ${ }^{34}$ Although a causal relationship was not definitely established, these trials highlight that hypoglycemia might precipitate other morbidities, such as dementia, as well. ${ }^{31}$ A recent study has reported a bidirectional association between hypoglycemia and dementia in elderly diabetic patients. ${ }^{35}$ Dementia could be associated with a decreased ability to manage medications. This is an important finding, since existing literature suggests an increased prevalence of hip fractures in elderly patients with dementia. ${ }^{36}$

\section{Limitations}

The key strength of this study is that it provides a real-world picture of elderly diabetic patients who experience hypoglycemia. Some of the limitations of this study include the use of ICD-9-CM codes for extracting relevant information. As such, there is potential for misclassification, since it is possible that some of these codes may be incorrectly entered in the database or on the claim form or might not have been entered at all. Potential for residual confounding also exists. The administrative databases may also lack information of some critical covariates. Also, this study may have missed patients who may have had severe hypoglycemia that resulted in death before hospital admission. This study may also have missed episodes of mild hypoglycemia that did not result in a doctor's visit or medical claim. The exclusion of events (e.g., fall or death) prior to the index date for the HG may introduce selection bias of lower risk than the general population. We also excluded death in the comparison group (bias of lower risk). There may be other limitations with regard to the generalizability of the study population, since the data do not include uninsured patients and are weighted towards patients who are able to afford supplemental Medicare health insurance, which may not represent the general U.S. population. In the database, we do not have information on whether these patients were previously employed or whether they had supplement health insurance from a previous employer. Due to nature of this study, estimating attributable risks for hypoglycemia was beyond the study's scope. Also, our study design only used a simple matching mechanism. We used conditional logistic regression to ana- lyze the matched pairs on age and sex, for the comparison of hypoglycemia groups, and these groups ended up having different frequencies in baseline characteristics. A more extensive matching or propensity score matching will be used in a future study to strengthen the argument and verify the associations found in this study.

\section{Conclusions}

This study shows an increased risk of fall-related events among elderly diabetic patients who experience hypoglycemia. This highlights the need to take preventive measures to reduce the incidence of hypoglycemia in elderly diabetic patients, which may thereby lead to a reduction of fall-related events. Welldesigned and conducted prospective studies are needed to further evaluate our findings.

\section{Authors}

SUMESH KACHROO, PhD, was, at the time of this study, Associate Director, Global Health Economics and Outcomes Research, BristolMyers Squibb, Nassau Park, New Jersey. HUGH KAWABATA, MS, is Director, CORDS, and SUSAN COLILLA, PhD, MPH, is Research Scientist, CORDS, Bristol-Myers Squibb, Hopewell, New Jersey. LIZHENG SHI, PhD, is Regents Associate Professor, Global Health Systems and Development, Tulane University, New Orleans, Louisiana, and Affiliated Researcher, Southeast Louisiana Veterans Health Care System, New Orleans; YINGNAN ZHAO, $\mathrm{PhD}$, is Affiliated Researcher, Southeast Louisiana Veterans Health Care System, New Orleans, and Assistant Professor, College of Pharmacy, Xavier University of Louisiana, New Orleans; JAYANTI MUKHERJEE, PhD, is Group Director, WWHEOR, Bristol-Myers Squibb, Wallingford, Connecticut; UCHENNA ILOEJE, MD, MPH, is Vice President, Alexion Pharmaceuticals, Cheshire, Connecticut; and VIVIAN FONSECA, MD, is Professor, Health Sciences Center, Tulane University, New Orleans, Louisiana.

AUTHOR CORRESPONDENCE: Lizheng Shi, PhD, Regents Associate Professor, School of Public Health and Tropic Medicine, Tulane University, 1440 Canal St., New Orleans, LA 70112. Tel.: 504.988.6548; Fax: 504.988.3783; E-mail: 1shi1@tulane.edu.

\section{DISCLOSURES}

This study was funded by an unrestrictive grant from Bristol-Myers Squibb to Tulane University.

Iloeje and Kachroo were employees of Bristol-Myers Squibb when this study was conducted and have no conflict of interest with regards to this study. Kawabata, Colilla, and Mukherjee are employees of Bristol-Myers Squibb. Zhao and Shi declare no conflict of interest with regards to this study. Fonseca has received grants from Novo Nordisk, Asahi, Eli Lilly, Abbott, and Endo Barrier, as well as honoria for consulting and lectures from GlaxoSmithKine, Takeda, Novo Nordisk, Sanofi-Aventis, Eli Lilly, Daiichi Sankyo, Pamlabs, Astra-Zeneca, Abbott, Bristol-Myers Squibb, Boehringer Ingelheim, and Janssen.

Results of this manuscript were presented at the European Association for the Study of Diabetes 49th Conference; Barcelona, Spain; 2013. 
Fonseca, Kachroo, Shi, Mukherjee, and Iloeje conceptualized the study design. Shi and Kawabata coordinated data analyses. Colilla conducted data analysis and consulted in the analysis plan. Shi and Kachroo led the development of the manuscript. All authors participated in interpreting the results and commenting on the manuscript.

\section{REFERENCES}

1. Danaei G, Finucane MM, Lu Y, et al. National, regional, and global trends in fasting plasma glucose and diabetes prevalence since 1980: systematic analysis of health examination surveys and epidemiological studies with 370 country-years and 2.7 million participants. Lancet. 2011;378(9785):31-40.

2. American Diabetes Association. Economic costs of diabetes in the U.S. in 2012. Diabetes Care. 2013;36(4):1033-46.

3. American Diabetes Association. Standards of medical care in diabetes2013. Diabetes Care. 2013;36(Suppl 1):S11-66.

4. Inzucchi SE, Bergenstal RM, Buse JB, et al. Management of hyperglycaemia in type 2 diabetes: a patient-centered approach. Position statement of the American Diabetes Association (ADA) and the European Association for the Study of Diabetes (EASD). Diabetologia. 2012;55(6):1577-96.

5. Inzucchi SE, Bergenstal RM, Buse JB, et al. Management of hyperglycemia in type 2 diabetes: a patient-centered approach: position statement of the American Diabetes Association (ADA) and the European Association for the Study of Diabetes (EASD). Diabetes Care. 2012;35(6):1364-79.

6. Liu S, Zhao Y, Hempe JM, Fonseca V, Shi L. Economic burden of hypoglycemia in patients with Type 2 diabetes. Expert Rev Pharmacoecon Outcomes Res. 2012;12(1):47-51.

7. Leese GP, Wang J, Broomhall J, et al. Frequency of severe hypoglycemia requiring emergency treatment in type 1 and type 2 diabetes: a populationbased study of health service resource use. Diabetes Care. 2003;26(4):1176-80.

8. Brito-Sanfiel M, Diago-Cabezudo J, Calderon A. Economic impact of hypoglycemia on healthcare in Spain. Expert Rev Pharmacoecon Outcomes Res. 2010;10(6):649-60.

9. Ha WC, Oh SJ, Kim JH, et al. Severe hypoglycemia is a serious complication and becoming an economic burden in diabetes. Diabetes Metab J. 2012;36(4):280-84

10. Lundkvist J, Berne C, Bolinder B, Jönsson L. The economic and quality of life impact of hypoglycemia. Eur J Health Econ. 2005;6(3):197-202.

11. Jönsson L, Bolinder B, Lundkvist J. Cost of hypoglycemia in patients with Type 2 diabetes in Sweden. Value Health. 2006;9(3):193-98.

12. Zhang Y, Weiffer H, Modha R, Balar B, Pollack M, Krishnarajah G. The burden of hypoglycemia in type 2 diabetes: a systematic review of patient and economic perspectives. J Clin Outcomes Manage. 2010;17(12):547-57.

13. Williams SA, Shi L, Brenneman SK, Johnson JC, Wegner JC, Fonseca V. The burden of hypoglycemia on healthcare utilization, costs, and quality of life among type 2 diabetes mellitus patients. J Diabetes Complications. 2012;26(5):399-406.

14. Englander F, Hodson TJ, Terregrossa RA. Economic dimensions of slip and fall injuries. J Forensic Sci. 1996;41(5):733-46.

15. Johnston SS, Conner C, Aagren M, Ruiz K, Bouchard J. Association between hypoglycaemic events and fall-related fractures in Medicare-covered patients with type 2 diabetes. Diabetes Obes Metab. 2012;14(7):634-43.

16. Wong CA, Recktenwald AJ, Jones ML, Waterman BM, Bollini ML, Dunagan WC. The cost of serious fall-related injuries at three Midwestern hospitals. Jt Comm J Qual Patient Saf. 2011;37(2):81-87.

17. Signorovitch JE, Macaulay D, Diener M, et al. Hypoglycaemia and accident risk in people with type 2 diabetes mellitus treated with non-insulin antidiabetes drugs. Diabetes Obes Metab. 2013;15(4):335-41.

18. Zhao Y, Campbell CR, Fonseca V, Shi L. Impact of hypoglycemia associated with antihyperglycemic medications on vascular risks in veterans with type 2 diabetes. Diabetes Care. 2012;35(5):1126-32.
19. Peel NM, Kassulke DJ, McClure RJ. Population-based study of hospitalised fall-related injuries in older people. Inj Prev. 2002;8(4):280-83.

20. Annest JL, Fingerhut LA, Gallagher SS, et al. Strategies to improve external cause-of-injury coding in state-based hospital discharge and emergency department data systems: recommendations of the CDC Workgroup for Improvement of External Cause-of-Injury Coding. MMWR Recomm Rep. 2008;57(RR-1):1-15.

21. Monami M, Cresci B, Colombini A, et al. Bone fractures and hypoglycemic treatment in type 2 diabetic patients: a case-control study. Diabetes Care. 2008;31(2):199-203.

22. Berlie HD, Garwood CL. Diabetes medications related to an increased risk of falls and fall-related morbidity in the elderly. Ann Pharmacother. 2010;44(4):712-17.

23. Kennedy RL, Henry J, Chapman AJ, Nayar R, Grant P, Morris AD. Accidents in patients with insulin-treated diabetes: increased risk of lowimpact falls but not motor vehicle crashes - a prospective register-based study. J Trauma. 2002;52(4):660-66.

24. Lapane KL, Yang S, Brown MJ, Jawahar R, Pagliasotti C, Rajpathak S. Sulfonylureas and risk of falls and fractures: a systematic review. Drugs Aging. 2013;30(7):527-47.

25. Quilliam BJ, Simeone JC, Ozbay AB. Risk factors for hypoglycemiarelated hospitalization in patients with type 2 diabetes: a nested case-control study. Clin Ther. 2011;33(11):1781-91.

26. Chelliah A, Burge MR. Hypoglycaemia in elderly patients with diabetes mellitus: causes and strategies for prevention. Drugs Aging. 2004;21(8):511-30.

27. Ozcelik F, Yiginer O, Arslan E, et al. Association between glycemic control and the level of knowledge and disease awareness in type 2 diabetic patients. Pol Arch Med Wewn. 2010;120(10):399-406.

28. Lingvay I. Hypoglycemia in type 2 diabetes-consequences and risk assessment. US Endocrinology. 2011;7(2):95-102. Available at: http://www. touchendocrinology.com/articles/hypoglycemia-type-2-diabetes-consequences-and-risk-assessment. Accessed February 6, 2015.

29. American Association of Clinical Endocrinologists. AACE releases new guidelines for diabetes management. Endocrine Today. May 2011. Available at: http://www.healio.com/endocrinology/diabetes/news/print/endocrinetoday/\%7Blcf478a0-c6b3-4389-9f65-15640b7cdcd7\%7D/aace-releases-newguidelines-for-diabetes-management. Accessed February 5, 2015.

30. Kenny C. When hypoglycemia is not obvious: diagnosing and treating under-recognized and undisclosed hypoglycemia. Prim Care Diabetes. 2014;8(1):3-11.

31. Global survey: need for improved hypoglycemia management for $\mathrm{T} 2$ diabetics. DiabetesCare.net. October 6, 2011. Available at: http://www. diabetescare.net/article/title/global-survey-need-for-improved-hypoglycemiamanagement-for-t2-diabetics. Accessed February 5, 2015.

32. Desouza CV, Bolli GB, Fonseca V. Hypoglycemia, diabetes, and cardiovascular events. Diabetes Care. 2010;33(6):1389-94.

33. Willis WD, Diago-Cabezudo JI, Madec-Hily A, Aslam A. Medical resource use, disturbance of daily life and burden of hypoglycemia in insulin-treated patients with diabetes: results from a European online survey. Expert Rev Pharmacoecon Outcomes Res. 2013;13(1):123-30.

34. Mathieu C, Filozof C, Barnett AH. Hypoglycaemia in type 2 diabetesclinical consequences and impact on treatment. European Endocrinology. 2010;6(1):29-34. Available at: http://www.touchendocrinology.com/articles/ hypoglycaemia-type-2-diabetes-clinical-consequences-and-impact-treatment. Accessed February 5, 2015.

35. Yaffe K, Falvey CM, Hamilton N, et al. Association between hypoglycemia and dementia in a biracial cohort of older adults with diabetes mellitus. JAMA Intern Med. 2013;173(14):1300-06.

36. Scandol JP, Toson B, Close JC. Fall-related hip fracture hospitalisations and the prevalence of dementia within older people in New South Wales, Australia: an analysis of linked data. Injury. 2013;44(6):776-83. 
APPENDIX A All Fall-Related Events by Group

\begin{tabular}{|c|c|c|c|c|c|c|c|c|}
\hline \multirow[b]{3}{*}{ Fall Events ${ }^{a, b}$} & \multirow[b]{3}{*}{ Total } & \multirow{2}{*}{\multicolumn{2}{|c|}{$\begin{array}{c}\text { Hypoglycemia Group } \\
\mathrm{N}=21,613\end{array}$}} & \multirow{2}{*}{\multicolumn{2}{|c|}{$\begin{array}{c}\text { Nonhypoglycemia Group } \\
\mathrm{N}=21,613\end{array}$}} & \multicolumn{3}{|c|}{ Conditional Logistic Regressionc } \\
\hline & & & & & & \multirow{2}{*}{$\begin{array}{l}\text { Relative } \\
\text { Risk }\end{array}$} & \multicolumn{2}{|c|}{ 95\% Confidence Limits } \\
\hline & & $\mathrm{N}$ & $\%$ & $\mathrm{~N}$ & $\%$ & & Lower & Upper \\
\hline Within 30 days & 272 & 235 & 1.09 & 37 & 0.17 & 5.6621 & 3.9817 & 8.0518 \\
\hline Aged $<75$ years & 117 & 107 & 0.50 & 10 & 0.05 & 9.5423 & 4.9815 & 18.2789 \\
\hline Aged $\geq 75$ years & 155 & 128 & 0.59 & 27 & 0.12 & 4.2285 & 2.7634 & 6.4703 \\
\hline Within 90 days & 491 & 373 & 1.73 & 118 & 0.55 & 2.8259 & 2.2841 & 3.4962 \\
\hline Aged $<75$ years & 211 & 165 & 0.76 & 46 & 0.21 & 3.2003 & 2.2907 & 4.4709 \\
\hline Aged $\geq 75$ years & 280 & 208 & 0.96 & 72 & 0.33 & 2.5870 & 1.9619 & 3.4113 \\
\hline Within 180 days & 724 & 520 & 2.41 & 204 & 0.94 & 2.3149 & 1.9625 & 2.7307 \\
\hline Aged $<75$ years & 319 & 238 & 1.10 & 81 & 0.37 & 2.6740 & 2.0675 & 3.4583 \\
\hline Aged $\geq 75$ years & 405 & 282 & 1.30 & 123 & 0.57 & 2.0818 & 1.6774 & 2.5838 \\
\hline Within 365 days & 1,071 & 720 & 3.33 & 351 & 1.62 & 1.8874 & 1.6573 & 2.1494 \\
\hline Aged $<75$ years & 470 & 335 & 1.55 & 135 & 0.62 & 2.2469 & 1.8327 & 2.7548 \\
\hline Aged $\geq 75$ years & 601 & 385 & 1.78 & 216 & 1.00 & 1.6640 & 1.4043 & 1.9718 \\
\hline
\end{tabular}

ancludes patients with baseline falls events.

${ }^{b}$ Composite fall events identified by ICD-9-CM codes 800.x-995.x and E codes E880-E888 occurring within 2 days.

${ }^{c}$ Matched on age and gender, and relative risk estimate adjusted for Charlson Comorbidity Index.

E code = ICD-9-CM Index to External Cause of Injury code; ICD-9-CM = International Classification of Diseases, Ninth Revision, Clinical Modification

APPENDIX B All Fall-Related Events by Group (Sensitivity Analyses: Excluding Insulin Users)

\begin{tabular}{|c|c|c|c|c|c|c|c|c|}
\hline \multirow[b]{3}{*}{ Fall Events ${ }^{\mathbf{a}, \mathbf{b}}$} & \multirow[b]{3}{*}{ Total } & \multirow{2}{*}{\multicolumn{2}{|c|}{$\begin{array}{c}\text { Hypoglycemia Group } \\
\mathrm{N}=15,925\end{array}$}} & \multirow{2}{*}{\multicolumn{2}{|c|}{$\begin{array}{c}\text { Nonhypoglycemia Group } \\
\mathrm{N}=15,925\end{array}$}} & \multicolumn{3}{|c|}{ Conditional Logistic Regression ${ }^{c}$} \\
\hline & & & & & & \multirow{2}{*}{$\begin{array}{c}\text { Relative } \\
\text { Risk }\end{array}$} & \multicolumn{2}{|c|}{ 95\% Confidence Limits } \\
\hline & & $\mathrm{N}$ & $\%$ & $\mathrm{~N}$ & $\%$ & & Lower & Upper \\
\hline Within 30 days & 209 & 186 & 1.17 & 23 & 0.14 & 7.1266 & 4.6003 & 11.0401 \\
\hline Aged $<75$ years & 86 & 81 & 0.51 & 5 & 0.03 & 14.3684 & 5.8114 & 35.5251 \\
\hline Aged $\geq 75$ years & 123 & 105 & 0.66 & 18 & 0.11 & 5.1225 & 3.0845 & 8.5072 \\
\hline Within 90 days & 380 & 293 & 1.84 & 87 & 0.55 & 2.9691 & 2.3206 & 3.7987 \\
\hline Aged $<75$ years & 156 & 124 & 0.78 & 32 & 0.20 & 3.3897 & 2.2701 & 5.0615 \\
\hline Aged $\geq 75$ years & 224 & 169 & 1.06 & 55 & 0.35 & 2.7262 & 1.9938 & 3.7276 \\
\hline Within 180 days & 564 & 407 & 2.56 & 157 & 0.99 & 2.3435 & 1.9437 & 2.8256 \\
\hline Aged $<75$ years & 235 & 178 & 1.12 & 57 & 0.36 & 2.8214 & 2.0809 & 3.8254 \\
\hline Aged $\geq 75$ years & 329 & 229 & 1.44 & 100 & 0.63 & 2.0744 & 1.6355 & 2.6311 \\
\hline Within 365 days & 834 & 561 & 3.52 & 273 & 1.71 & 1.8934 & 1.6354 & 2.1921 \\
\hline Aged $<75$ years & 343 & 249 & 1.56 & 94 & 0.59 & 2.4182 & 1.9016 & 3.0750 \\
\hline Aged $\geq 75$ years & 491 & 312 & 1.96 & 179 & 1.12 & 1.6193 & 1.3442 & 1.9507 \\
\hline \multicolumn{9}{|c|}{$\begin{array}{l}{ }^{b} \text { Composite fall events identified by ICD-9-CM codes 800.x-995.x and E codes E880-E888 occurring within } 2 \text { days. } \\
{ }^{c} \text { Matched on age and gender, and relative risk estimate adjusted for Charlson Comorbidity Index. } \\
\text { E code }=I C D-9-C M \text { Index to External Cause of Injury code. ICD-9-CM =International Classification of Diseases. Ni }\end{array}$} \\
\hline
\end{tabular}


APPENDIX C Specific Fall-Related Outcomes (Within 365 Days Only) by Age Subgroups

\begin{tabular}{|c|c|c|c|c|c|c|c|c|}
\hline \multirow[b]{3}{*}{ Fall Events } & \multirow[b]{3}{*}{ Total } & \multirow{2}{*}{\multicolumn{2}{|c|}{$\begin{array}{l}\text { Hypoglycemia Group } \\
\mathrm{N}=21,613\end{array}$}} & \multirow{2}{*}{\multicolumn{2}{|c|}{$\begin{array}{c}\text { Nonhypoglycemia Group } \\
\mathrm{N}=21,613\end{array}$}} & \multicolumn{3}{|c|}{ Conditional Logistic Regressionc } \\
\hline & & & & & & \multirow{2}{*}{$\begin{array}{l}\text { Relative } \\
\text { Risk }\end{array}$} & \multicolumn{2}{|c|}{ 95\% Confidence Limits } \\
\hline & & $\mathrm{N}$ & $\%$ & $\mathrm{~N}$ & $\%$ & & Lower & Upper \\
\hline All fracture-related events & 445 & 308 & 1.43 & 137 & 0.63 & 2.1061 & 1.7140 & 2.5878 \\
\hline Aged $<75$ years & 182 & 129 & 0.60 & 53 & 0.25 & 2.2662 & 1.6339 & 3.1433 \\
\hline Aged $\geq 75$ years & 263 & 179 & 0.83 & 84 & 0.39 & 2.0048 & 1.5376 & 2.6139 \\
\hline All head injury-related events & 222 & 145 & 0.67 & 77 & 0.36 & 1.7696 & 1.3279 & 2.3582 \\
\hline Aged $<75$ years & 85 & 58 & 0.27 & 27 & 0.12 & 2.0061 & 1.2513 & 3.2162 \\
\hline Aged $\geq 75$ years & 137 & 87 & 0.40 & 50 & 0.23 & 1.6413 & 1.1422 & 2.3585 \\
\hline All fall-related hospital admissions & 184 & 128 & 0.59 & 56 & 0.26 & 2.1541 & 1.5596 & 2.9753 \\
\hline Aged $<75$ years & 62 & 46 & 0.21 & 16 & 0.07 & 2.4424 & 1.3283 & 4.4910 \\
\hline Aged $\geq 75$ years & 122 & 82 & 0.38 & 40 & 0.19 & 2.0532 & 1.4042 & 3.0022 \\
\hline $\begin{array}{l}\text { All composite fall-related outcomes for } \\
\text { patients with long-term care placement }\end{array}$ & 260 & 186 & 2.20 & 74 & 0.87 & 2.3623 & 1.7954 & 3.1084 \\
\hline Aged $<75$ years & 88 & 69 & 0.81 & 19 & 0.22 & 3.3522 & 2.0132 & 5.5817 \\
\hline Aged $\geq 75$ years & 172 & 117 & 1.38 & 55 & 0.65 & 2.0200 & 1.4537 & 2.8071 \\
\hline
\end{tabular}

